MIDPI

MOL2NET, International Conference Series on Multidisciplinary Sciences

sciforum,

\title{
THE DIAGNOSIS AND TREATMENT OF NIEKMANN PICK DISEASE
}

\author{
K.Madhubabu, M.Preethi, B.Hemanthkumar, Gangarapu.Kiran, D.Krishnaprasad \\ Department of Pharmacology, Anurag Group of Institutions (School of Pharmacy), Ghatkesar, \\ Hyderabad, Telangana state, India
}

\begin{abstract}
.
Niekmann-Pick disease (NPD) is an lipid storage disorder called as Sphingnomyllinase. The NPD has highly prevalent in worldwide according to recent epidemiology the populations of NPD 20,099 in the year 2016 for major markets covering US, EU5 (Germany, Spain, France, Italy) and Japan. It is an group of disorders with two different classes;(1) Acid sphingomyelinase deficient Niekmann-Pick disease (ASM-deficient NPD) resulting from mutations in the SMPD1 gene and encompassing type A and type B as well as intermediate forms; (2) Niekmann-Pick disease type C (NP-C) including also type $\mathrm{D}$, resulting from mutations in either the $N P C 1$ or the $N P C 2$ gene. For type $\mathrm{A}$ and $\mathrm{B}$, levels of sphingomylinase can be measured from a blood sample. To diagnose type $\mathrm{C}$, a skin sample can help determine whether the transporter is affected. Treatment for NPD as there is no effective available for type A. Type B can be cured by for Bone marrow transplantation. A newly approved drug Miglustat (glucosylcermide synthase inhibitor) has approved for type $\mathrm{C}$ and also Hydroxy-propyl betacyclodextrin $(\mathrm{HpbcD})$ as potential treatment for NPD. Individuals with NPD type C and type D are frequently placed on low cholesterol diet $\&$ cholesterol lowering drugs. . The present review describes the diagnosis, treatment, symptoms and number of patients suffered in the Asia countries have presented.
\end{abstract}

\section{Introduction (optional)}

Materials and Methods (optional)

\section{Results and Discussion (optional)}


Conclusions (optional)

\section{References(mandatory)}

1. Abi-Mosleh L, Infante RE, Radhakrishnan A, Goldstein JL, Brown MS. Cyclodextrin overcomes deficient lysosome-to-endoplasmic reticulum transport of cholesterol in Niemann-Pick type C cells. Proc Natl Acad Sci U S A. 2009;106:19316-21.

2. Stern G. Niemann-Pick's and Gaucher's diseases. Parkinsonism Relat Disord. 2014. Jan;20 Suppl 1:S143-6.

3. Chien YH, Peng SF, Yang CC, Lee NC, Tsai LK, Huang AC, Su SC, Tseng CC, Hwu WL. Longterm efficacy of miglustat in paediatric patients with Niemann-Pick disease type C. J Inherit Metab Dis. 2013;36:129-37.

4. Fecarotta S, Amitrano M, Romano A, Della Casa R, Bruschini D, Astarita L, Parenti G, Andria G. The videofluoroscopic swallowing study shows a sustained improvement of dysphagia in children with Niemann-Pick disease type C after therapy with miglustat. Am J Med Genet A. 2011;155A:540-7.

5. Belmatoug N, Burlina A, Giraldo P, et al. Gastrointestinal disturbances and their management in miglustat-treated patients. J Inherit Metab Dis 2011;34:991-1001.

6. Amiri M, Naim HY. Miglustat-induced intestinal carbohydrate malabsorption is due to the inhibition of $\alpha$-glucosidases, but not $\beta$-galactosidases. J Inherit Metab Dis 2012;35:949-54. 